\title{
UAE Elementary Teachers' Use of ADHD Referral and Management Strategies
}

\author{
Hala Elhoweris, Ahmed Mohamed, Osha Almuhairy, \\ Rachel Takriti and Najwa Alhosani \\ United Arab Emirates University, UAE \\ https:// orcid.org/0000-0002-1461-4404 \\ https:// orcid.org/0000-0002-8225-2310 \\ https://orcid.org/0000-0002-2284-7419 \\ https://orcid.org/0000-0002-7920-3198 \\ https://orcid.org/0000-0002-1487-9496 \\ Abdelaziz Sartawi \\ Dar Zayed for Care Family \\ https://orcid.org/0000-0001-6837-8745
}

\begin{abstract}
The purpose of this study was four-fold: to identify factors teachers perceive to contribute to their referral of students with attention deficit and hyperactivity disorder (ADHD); to examine management strategies elementary teachers in the UAE use; to examine the effect years of teaching experience, domain (general versus special education teachers) and experience teaching children with ADHD have on their use of referral and management strategies, and; to explore the relationship between teachers' use of referral and management strategies. The ADHD Referral Scale and the ADHD Management Strategies Questionnaire (AMSQ) were completed by 52 elementary special and general education teachers. The results of the study revealed that inattention/distractibility was perceived by both the special and general education teachers to be a contributing factor for referring students with ADHD to special education services. The general education teachers also noted hyperactivity to be a contributing factor. The findings further revealed that while special and general education teachers employed behaviour and academic intervention strategies, special education teachers frequently used home/parent intervention strategies. Finally, the MANOVA analyses showed a significant main effect of teaching experience and teachers' experience with ADHD.
\end{abstract}

Keywords: ADHD; elementary school teachers; management strategies; referral; UAE 


\section{Introduction}

The number of students with attention deficit and hyperactivity disorder (ADHD) varies among countries (Salehi, Noah \& Jaafar, 2011). Globally, according to Liu, $\mathrm{Xu}$, Yan and Tong (2018), the prevalence rates of ADHD vary between $1 \%$ to about $20 \%$ among children and adolescents across the world. The number of children diagnosed with ADHD around the world is increasing and it has changed over time. According to Bu-Haroon, Eapen and Bener (1999), the prevalence rate of ADHD in Al-Sharjah elementary schools is approximately $14.9 \%$. Although the prevalence rate of ADHD among Sharjah elementary school children is high, there is no valid standardized rating scale to diagnose children with ADHD in the UAE. Furthermore, it is unclear how school teachers identify and/or manage the behaviours of students with ADHD in the UAE (Elhoweris, 2014).

ADHD is a developmental disorder that is defined by the American Psychiatric Association (2013) as a continuous pattern of specific behaviours, including inattention, overactivity, and impulsivity. Children with ADHD have a significant poor attention span in comparison to their peers. Recently, various changes have been evident in the diagnosis of ADHD. According to the $5^{\text {th }}$ edition of the Diagnostic and Statistical Manual of Mental Disorders (DSM-V), for a diagnosis of ADHD, symptoms must occur by the age of 12 years. Furthermore, it is imperative that several symptoms are present in more than one setting. Also, the $10^{\text {th }}$ revision of the International Statistical Classification of Diseases and Related Health Problems (ICD) defined ADHD as a state of overactive restlessness, particularly in children, marked by extreme excess of motor activity, restlessness, fidgeting, aggressive-like behaviour and impulsivity. According to the ICD-10, school children with ADHD cannot sit still and comply with rules, and also exhibit low frustration levels (Doernberg \& Hollander, 2016).

Identifying children with ADHD is complex because young children who are naturally energetic may become even more active when they are tired, hungry, and/or exposed to a new environment. Although such children may not have ADHD, they may be labelled as having ADHD. Fabiano et al. (2013) noted that teachers define ADHD loosely and have a tendency of overestimating the number of children with ADHD. It is common for challenging children to be incorrectly labelled as having ADHD. On the contrary, many children who do have ADHD are not diagnosed as such. However, early and effective identification is imperative to ensure that children are given the opportunity to realise their full potential. Consequently, an understanding of the referral process in the UAE is necessary.

The impact of ADHD on an individual's psychological development, education, relationships, and family is immeasurable. Attention problems are prevalent among students with ADHD (Salend, 2015). Findings gleaned from a previous study suggested that approximately $16 \%$ of elementary school children have difficulty in concentrating and paying attention during class activities (Rabiner \& Malone, 2004). Additionally, Bener, Al Qahtani and Abdelaal (2006) found that students with higher symptoms of ADHD perform lower at school in comparison to those children with lower symptoms of ADHD. In addition to the negative 
impact of poor attention span among children with ADHD on academic achievement (Faraone et al., 2015), attention problems are also associated with behavioural issues and poor engagement with school-related activities (Rushton, Giallo \& Efron, 2019). Students with ADHD engage in several high-activity behaviours when in class, including fidgeting with their hands and objects, calling out, not sitting when they should, talking excessively and interrupting others (Salend, 2015). From a social perspective, students with ADHD often exhibit several inappropriate behaviours including stubborn, unhelpful, destructive, insensitive, hostile, impulsive, unpleasant, and bossy behaviours that result in their being rejected by their peers and adults (Friend \& Bursuck, 2018). Furthermore, child mental health problems are more closely related to studentteacher conflict than to closeness (e.g., Drugli, 2013; Ewe, 2019; Portilla, Ballard, Adler, Boyce \& Obradovic, 2014). According to Rushton et al. (2019), children who exhibited higher ADHD symptoms in their early school years, they felt less positive about their school and learning in the later elementary school grades.

Throughout the years, several studies on various types of interventions for children with ADHD have been conducted. Although the prescription of psychostimulant medication is the most common intervention for students with ADHD (Barkley, 2020), academic and behavioural interventions have demonstrated to be very effective (DuPaul, Eckert \& Viladro, 2012; Miranda, Jarque \& Tarraga, 2006; Salend, Elhoweris \& VanGarderen, 2003; Schultz, Storer, Watabe, Sadler \& Evans, 2011). Literature has shown that ADHD does not only affect the sufferers, but also the people around them, especially, family members, teachers, and friends. Accordingly, it is widely accepted that the most effective treatment for ADHD comprises a combination of strategies rather than only one single course of action. Miranda et al. (2006) noted the necessity of expanding the intervention repertoire to meet the unique needs of children with ADHD by considering a multimodal intervention, which includes different types of interventions. The multimodal intervention frequently includes medical intervention in conjunction with parent intervention, school intervention, and child intervention. Classroom management is a complex skill that comprises employing academic, behavioural and/or combined intervention strategies to address students' inappropriate behaviours (Epstein, Atkins, Cullinan, Kutash \& Weaver, 2008; Korpershoek, Harms, de Boer, van Kuijk \& Doolaard, 2016).

Although considerable evidence related to the academic and social difficulties children with ADHD experience abounds, not much is known about teachers' actions and knowledge. Previous studies have revealed that because of a lack of training, primary school teachers experience difficulties understanding and managing ADHD behaviours (Arcia, Frank, Sanchez-LaCay \& Fernaindez, 2012). Öner, Vatanartiran and Karadeniz (2019) found that teachers reported ADHD symptoms 2.5 to 3.6 times more often in students who were young for their grade. Furthermore, previous studies have demonstrated that teachers usually lack knowledge of ADHD and how it may affect the social and academic achievement of students with ADHD (Gwernan-Jones et al., 2016; Ljusberg, 2011). However, Ohan, Visser, Strain and Allen (2011) found that teachers who had considerable knowledge of ADHD had healthier attitudes towards children with ADHD and 
treated them more positively. In a study that examined in-service teachers' knowledge of classroom management procedures, Owens et al. (2017) found that in-service teachers lack the awareness to meet the behavioral demands of children with ADHD. Reinke, Stormont, Herman, Puri and Goel (2011) revealed that earlychildhood and elementary in-service teachers lack the necessary knowledge and skills to address the needs of those students with mental health problems. Furthermore, in a U.S. national study, in-service teachers reported that they used low-intensity behavioural support such as praise and reprimands and antecedents control to manage their students' behaviours (cited in Poznanski, Hart \& Cramer, 2018). In a study, in Africa, that examined teachers' knowledge about ADHD, the use of management strategies and the relationship between teachers' knowledge and management strategy use it has been found that although teachers knew about ADHD diagnosis and symptoms, teachers were found to have less knowledge about ADHD evidence-based interventions. Additionally, there was no significant correlation between teachers' knowledge about ADHD and classroom practices (Blotnicky-Gallant, Martin, McGonnell \& Corkum, 2014). Findings of a research study that examined Saudi teachers' knowledge of ADHD characteristics, causes, and appropriate interventions revealed that Saudi teachers had some knowledge about general characteristics of ADHD and little knowledge about the causes and appropriate treatments for ADHD (Abed, Pearson, Clarke \& Chambers, 2014).

Martinussen, Tannock and Chaban (2011) investigated the level of in-service training in ADHD among general and special education teachers, as well as the relationship between teacher training in ADHD and the use of instructional and behaviour management approaches. They found that the participating teachers, including general and special education teachers, had no or hardly any in-service training in ADHD. Furthermore, the general education teachers with moderate to extensive in-service training in ADHD noted significantly higher use of the management strategies than the general education teachers with hardly any or no training in ADHD. Vereb and DiPerna (2004) found that there is a significant positive correlation between ADHD training and teachers' awareness of ADHD and behaviour management strategies. More specifically, the teachers who participated in ADHD training demonstrated more knowledge about ADHD and acceptability of the management strategies for ADHD children. Additionally, findings from recent studies that examined the impact of training programs on teachers' knowledge of ADHD and ADHD intervention and attitudes toward students with ADHD revealed that teachers who participated in training programs showed higher scores on ADHD knowledge, attitudes and behavioral interventions for ADHD students (Alabd, Mesbah \& Alboliteeh, 2018; Lasisi, Ani, Lasebikan, Sheikh \& Omigbodun, 2017). Sciutto et al. (2016) conducted a study with teachers from four different continents comprising Europe, America, Asia, and Africa to examine the relationship between teachers' prior experience with ADHD and receipt of ADHD training and teachers' knowledge of ADHD. Findings of this study indicated that some form of ADHD training and prior experience with ADHD students' variables were associated with more teachers' knowledge of ADHD in the majority of the participating countries in this study. 
Students with ADHD in the UAE are placed in general education classes. Therefore, the inputs from general and special education teachers are imperative for identifying ADHD and addressing the sufferers' needs. Although diagnosing children with ADHD is complex, there is an unexpected lack of empirical evidence related to teachers' referral decisions and their reasons thereof for students with ADHD in the UAE. Furthermore, it is unclear what types of interventions have been employed for children with ADHD in the country. Accordingly, the purpose of this study was four-fold: first, to identify factors teachers perceive to contribute to their referral and management of students with ADHD; second, to examine management strategies elementary teachers in the UAE use; third, to examine the effect years of teaching experience, domain (general versus special education teachers) and experience teaching children with ADHD have on their use of referral and management strategies; and finally, to explore the relationship between teachers' use of referral and management strategies.

\section{Methodology}

\subsection{Participants}

Random sampling was employed to maximize the demographic and geographic diversity across the sample. The participants included 52 teachers $(71 \%$ general educators and $29 \%$ special educators) who taught in UAE government schools. The participants were recruited from six elementary schools from different Emirates. Of the 52 teachers who completed the questionnaire, 15 were special education teachers and 37 general education teachers. Furthermore, the majority of the participants had a bachelor's degree. Of the participants, 44 were female and 8 were male. Finally, the majority of the participants indicated that they had been teaching for more than ten years. The participants' demographic information is displayed in Table 1.

Table 1: Study Sample Demographic Variables

\begin{tabular}{llc}
\hline Variable & Category & $N$ \\
\hline Years of teaching & 1-3 years & 13 \\
experience & 4-6 years & 6 \\
& 7-9 years & 8 \\
Gender & 10+ years & 25 \\
& Male & 8 \\
Educational level & Female & 44 \\
& high school & 1 \\
& Diploma & 1 \\
Domain & Bachelor & 45 \\
& Higher education & 5 \\
Experience with ADHD & Special education & 15 \\
& General education & 37 \\
& No experience & 14 \\
& Moderate & 22 \\
& High & 16 \\
\hline
\end{tabular}




\subsection{Instruments}

\subsubsection{The ADHD Referral Scale}

The ADHD Referral Scale comprises items that assess the likelihood of teachers referring students with ADHD. The scale assesses whether students who should be referred for special education needs assistance typically display particular behaviours. The questionnaire comprises 36 items, which are assessed on a fourpoint Likert scale, ranging from 4 (Always) to 1 (Rarely). To develop the scale, several sources were examined, including the diagnostic criteria for ADHD specified in the DSM-V, ICD-10, various instruments, well-known books and scholarly articles on ADHD (e.g., Salend, 2015; Tannock \& Martinussen, 2001). To ensure the content validity of the scale, four academics from special education and psychology departments of universities rated the domains and the items included in the scale. These specialists rated each item based on the degree it reflects the skill it is supposed to measure, precision of the language and ability to observe the skill targeted. The percentage of agreement amongst the specialists was $80 \%$, which provided evidence of each item's level of content validity. The participants were also required to provide their demographic information, including the number of years they had taught, whether they were trained as special needs or general education teachers and their gender. They were subsequently asked to indicate their level of experience with ADHD students by classifying themselves into one of three categories' namely, highly experienced, moderately experienced and inexperienced.

The initial examination of the sample size was performed by employing Bartlett's Test of Sphericity. The results of this analysis indicated that the sample was adequate. Furthermore, correlation matrix analysis showed that all the items were positively inter-correlated. Exploratory factor analysis with oblique rotation was performed by employing SPSS. Factors were identified in accordance with Kaiser's rule of Eigenvalue greater than one and confirmed by an examination of the scree plot. The items had to load on a single factor with an absolute value of .50 or higher. Principal components factor analysis with oblimin rotation was performed to identify which items loaded onto similar factors. Three factors emerged, which accounted for $70.16 \%$ of the total variance. In Table 2, the items that loaded onto each factor are displayed. The items were employed to create a scale and reliability analysis was performed for each factor. Cronbach's alpha exceeded .70 and thus, the scales were deemed to be reliable. This information is also presented in Table 2. The three scales measured the following referral behaviours: inattention/distractibility, hyperactivity and disruptive behaviours.

Table 2: Sub-scales, Cronbach's alpha of the ADHD Referral Questionnaire

\begin{tabular}{clc}
\hline Scale 1: Inattention/Distractibility & $\begin{array}{c}\text { Cronbach's } \\
\text { alpha .86 }\end{array}$ \\
\hline $\mathrm{N}$ & \multicolumn{1}{c}{ Item } & \\
1 & Quiet often does not seem to listen when talking to him & \\
2 & Most of the time cannot complete his/her homework on time & \\
3 & Often has difficulty organizing tasks and activities & \\
4 & Often forgets the necessary school supplies & \\
5 & Always makes trivial or careless mistakes in homework & \\
\hline
\end{tabular}




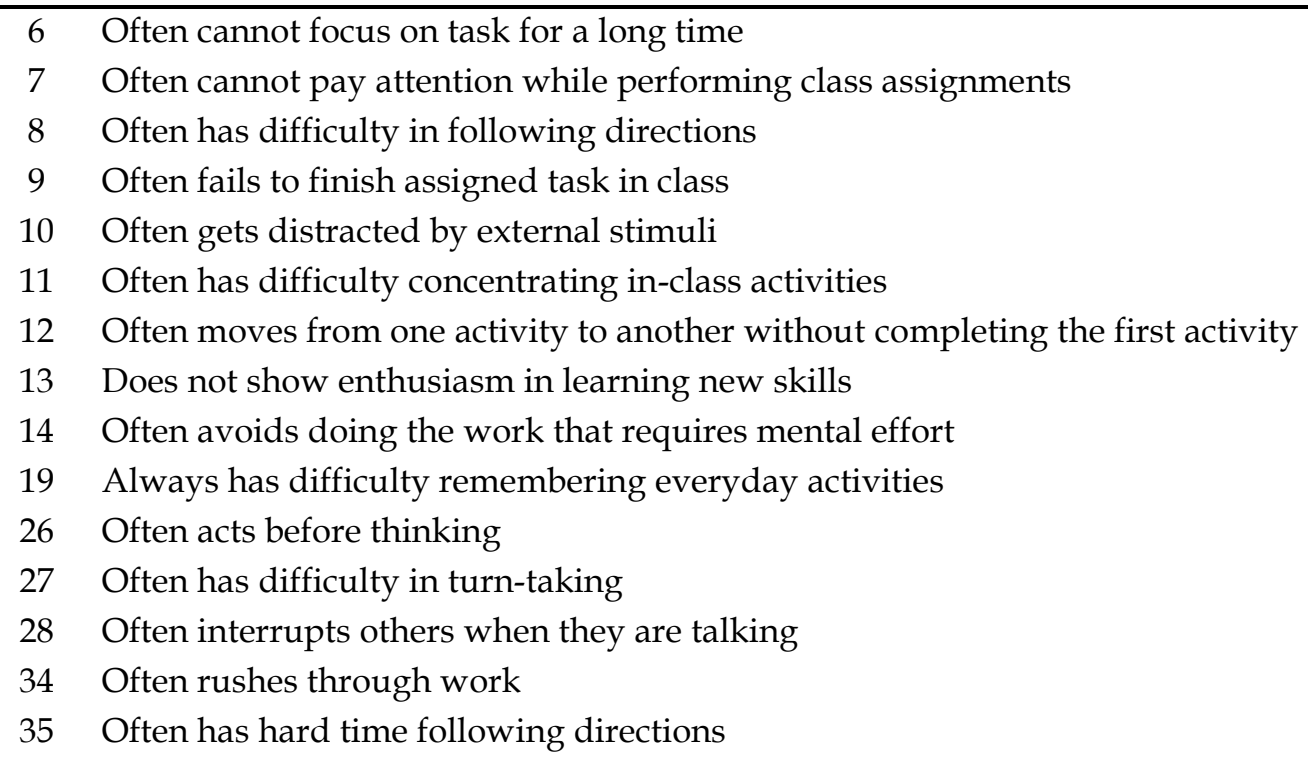

Scale 2: Hyperactivity

Cronbach's alpha .79

\begin{tabular}{ll}
\hline $\mathrm{N}$ & \multicolumn{1}{c}{ Item } \\
15 & Achieves below academic expectations \\
16 & Always on the move in or outside the classroom \\
17 & Always on the move in and outside the classroom \\
18 & Often has difficulty sitting quietly for a long time compared to his/her peers \\
20 & Often jumps in situations in which it is inappropriate \\
21 & Often fidgets with hands and moves his/her feet constantly \\
22 & Often speaks and is noisy in the classroom \\
23 & Often overtly expresses distress \\
24 & Talks excessively in the classroom \\
25 & Often plays with things in the classroom \\
32 & Often he/she cannot control his/her reaction to various situations
\end{tabular}

Scale 3: Disruptive Behaviours

Cronbach's alpha .81

\begin{aligned} & \hline N \multicolumn{1}{c}{ Item } \\ & 29 Often breaks or damages things inside the classroom \\ & 30 Often breaks or destroys things outside the classroom \\ & 31 Always fights with others \\ & 33 Often blurts out \\ & 36 Lacks social skills \\ & \hline\end{aligned}




\subsubsection{The ADHD Management Strategies Questionnaire (AMSQ).}

The AMSQ, the second instrument employed, was developed to identify management strategies used by elementary school teachers to reduce ADHD children's disruptive behaviours. The questionnaire comprises 19 items, which are assessed on a four-point Likert scale, ranging from 1 (rarely) to 4 (always). All the items in the AMSQ were derived from the literature to ensure content validity. The researchers also used their clinical judgment to select the items. The content validity of the AMSQ was assessed by three specialists in the field of special education who were asked to determine the intended content. The percentage of agreement amongst the specialists was $75 \%$. The researchers tested the two questionnaires to determine whether the instruments were clear and appropriate. The reliability of the AMSQ instrument was established by administering the Referral Scale and AMSQ on 20 elementary teachers and readministered two weeks after its initial administration. The correlation between individuals' first and second scores was high $(r=.88, p<.01)$.

Principal components factor analysis with oblimin rotation was employed to identify which items loaded onto similar factors. Three factors emerged, which accounted for $62.03 \%$ of the total variance. In Table 3, the items loaded onto each factor are displayed. The items were employed to create a scale and reliability analysis was conducted for each factor. Cronbach's alpha exceeded .60 in each instance and thus, the scales were deemed to be reliable; this is presented in Table 3. The following types of management were measured by the three scales: behavioural intervention, home/parent intervention and academic intervention.

Table 3: Sub-scales, Cronbach's alpha of the ADHD Management Strategies Questionnaire

\footnotetext{
Scale 1: Behaviour Intervention Cronbach's alpha .85

\begin{tabular}{cc}
$\mathrm{N}$ & Item \\
\hline 1 & Use positive words, smiles and gifts in reducing hyperactivity, impulsivity,
\end{tabular} and/or inattention behaviours.

5 Allow children with ADHD to play quietly and with educational games in my classroom.

6 Minimize classroom tasks or assignment for students with ADHD.

7 Assign responsibilities (e.g., a trip to the office, turning on the computer) for students with ADHD to use their excessive amount of energy.

9 Use technology in my teaching to help children with ADHD focus in my classroom.

10 Encourage my students to use self-management strategies to deal with their high activity behaviours.

11 Give students with ADHD an opportunity to have a choice of classroom activities.

12 Use positive and negative reinforcement to reduce hyperactivity and/or inattention problems.

16 Frequently reinforce the classroom rules through visible modes of presentation.
} 


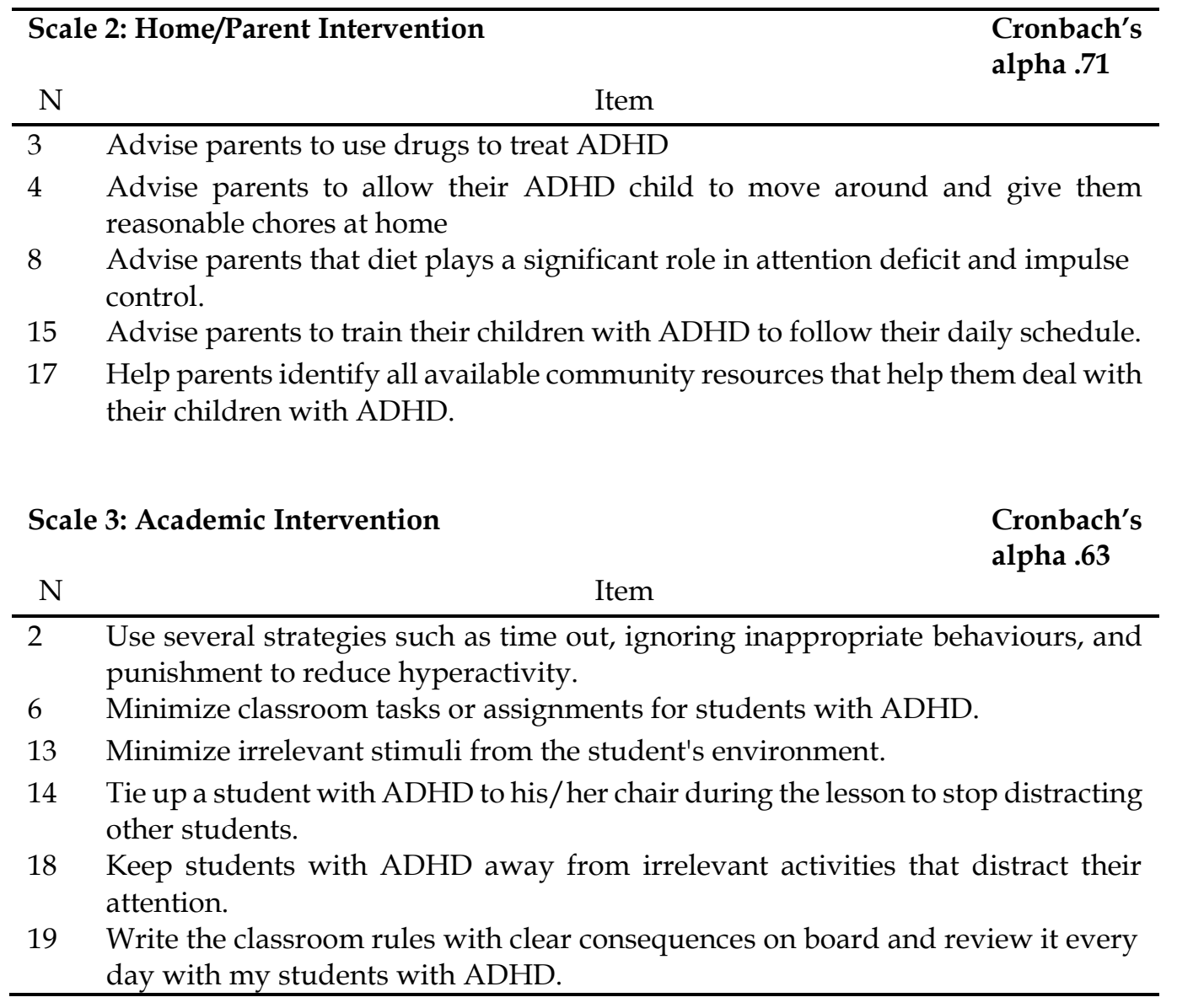

\section{Results}

To determine what factors teachers perceive to contribute to referring students with ADHD to special education services, a one-sample $t$-test was conducted to examine the statistical difference between the sample mean and a hypothesized or virtual mean (2.5). This hypothesized mean was obtained by dividing the sum of the Likert categories ( 1 to 4 ) by four. The results are presented in Table 4 . Special education teachers perceived inattention/distractibility to be a contributing factor for referring students with ADHD, $t(14)=2.65, p<.01$. However, general education teachers perceived inattention/distractibility, $t(36)=3.90, p<.01$ and hyperactivity, $(t(36)=6.18, p<.01)$ to be contributing factors.

To determine what management strategies UAE general and special education teachers use primarily when dealing with students with ADHD, a one-sample ttest was conducted to examine the statistical difference between the sample mean and a hypothesized or virtual mean (2.5). The results revealed that the management strategies that were frequently used by special education teachers included behaviour intervention, $t(14)=4.28, p<.01$, home/ parent intervention, $t(14)=2.76, p<.01$ and academic intervention, $t(14)=2.15, p<.01$, general education teachers frequently used behaviour intervention, $t(36)=8.45, p<.01$ and academic intervention, $t(36)=3.95, p<.01$. 
Table 4: Means, Standard Deviations, and One-Sample t-test results of the ADHD Referral Questionnaire

\begin{tabular}{lcccccc}
\hline & \multicolumn{3}{c}{$\begin{array}{c}\text { General Education } \\
\text { Teachers }(d f=36)\end{array}$} & $\begin{array}{c}\text { Special Education Teachers } \\
(d f=14)\end{array}$ \\
\hline & $M$ & $S D$ & $t$ & $M$ & $S D$ & $t$ \\
Behaviour intervention & 3.20 & 0.50 & $8.45^{* *}$ & 3.28 & 0.69 & $4.38^{* *}$ \\
Home/parent intervention & 2.59 & 0.64 & 0.90 & 2.92 & 0.59 & $2.76^{* *}$ \\
Academic intervention & 2.83 & 0.51 & $3.96^{* *}$ & 2.84 & 0.62 & $2.15^{* *}$ \\
Inattention/distractibility & 2.87 & 0.58 & $3.90^{* *}$ & 2.94 & 0.65 & $2.65^{* *}$ \\
Hyperactivity & 3.00 & 0.49 & $6.18^{* *}$ & 2.83 & 0.67 & 1.90 \\
Disruptive behaviours & 2.70 & 0.64 & 1.88 & 2.59 & 0.84 & 0.40 \\
\hline
\end{tabular}

To determine the effect of years of teaching experience, domain (general versus special education teachers), and teachers' experience of ADHD on the referral and management subscales, a multivariate analysis of variance (MANOVA) was conducted. Whereas the independent variables included teachers' experience, domain, and teachers' experience with ADHD, the dependent variables comprised the subscales of the referral and management questionnaires. The use of MANOVA allowed for the control of type I errors. Levene's test of equality of error variances for the dependent variables was not statistically significant $(p>$ .05). The means, standard deviations, $F$ values, and eta squared values are displayed in Table 5. The results revealed a significant main effect of years of teaching experience; Wilks' Lambda $F(6,21)=14.16, \mathrm{p}<.01, \eta 2=.35$ for behaviour intervention and Wilks' Lambda $F(6,21)=5.30, p<.05, \eta 2=.20$ for home/parent intervention. To analyse the main effect, Bonferroni tests were employed as posthoc measurements. Effect sizes were interpreted as follows: $.01=$ small, $.06=$ medium, and $.14=$ large (Cohen, 1988). The results revealed that the effect size of the main effect of teachers' experience for the two subscales was large. Post-hoc analyses revealed that those who had ten years or more experience scored significantly higher than those who had taught between one and three years in both the behaviour intervention subscale, $F(1,26)=14.66, p<.01, \eta 2=.35$ and the home/parent intervention subscale, $F(1,26)=5.30, p<.05, \eta 2=.17$. The MANOVA results also revealed a significant main effect of teachers' experience with ADHD; Wilks' Lamda $F(12,42)=3.58, p<.05, \eta 2=.28$ for the inattention/distractibility subscale and Wilks' Lamda $F(12,42)=4.95, p<.05, \eta 2$ $=.22$ for the hyperactivity subscale. The effect size of this main effect was large. Post-hoc analyses showed that the group with moderate experience of ADHD scored significantly higher than the group with much experience in the hyperactivity subscale, $F(2,26)=3.57, p<.05, \eta 2=.22$. The group with moderate experience also scored significantly higher than the inexperienced group, $F(2,26)$ $=4.95, p<.01, \eta 2=.28$. The main effect of the domain (special versus general education teachers) was not statistically significant. 
Table 5: Means, Standard Deviations, F values, and eta Squared Values of Years of Teaching Experience, Domain, and Experience with ADHD

\begin{tabular}{lcc}
\hline Subscale & Teachers' experience & \\
& $\boldsymbol{F}(\mathbf{6}, \mathbf{2 1})$ & $\mathbf{\eta}^{\mathbf{2}}$ \\
\hline Behaviour intervention & $14.16^{* *}$ & .35 \\
Home/ parent intervention & $5.30^{*}$ & .20 \\
Academic intervention & 2.66 & .09 \\
Inattention/distractibility & 1.01 & .02 \\
Hyperactivity & .003 & .001 \\
Disruptive behaviours & .074 & .009 \\
& Domain & \\
\hline & $F(6,21)$ & $\eta^{2}$ \\
Behaviour intervention & 1.07 & .04 \\
Home/parent intervention & .01 & .00 \\
Academic intervention & .41 & .02 \\
Inattention/distractibility & .23 & .01 \\
Hyperactivity & 1.37 & .05 \\
& & \\
\hline & ADHD Experience & $\eta^{2}$ \\
Behaviour intervention & $F(12,42)$ & .04 \\
Home/parent intervention & .47 & .07 \\
Academic intervention & .91 & .17 \\
Inattention/distractibility & 2.74 & .22 \\
Hyperactivity & $3.58 *$ & .28 \\
Behaviour intervention & $4.95 *$ & .04 \\
\hline
\end{tabular}

Pearson product-moment correlation was used to explore the relationship between the referral and management subscales. The results showed that there was a positive correlation between the academic intervention subscale and the inattention/distractibility subscale, $r=.46, p<.01$. The relationships among the subscales of the two scales are presented in Table 6.

Table 6: Correlations among the Subscales of the Two Questionnaires

\begin{tabular}{|c|c|c|c|c|c|c|}
\hline & $\begin{array}{l}\text { Behavio } \\
\text { ur } \\
\text { intervent } \\
\text { ion }\end{array}$ & $\begin{array}{l}\text { Home/ } \\
\text { parent } \\
\text { intervent } \\
\text { ion }\end{array}$ & $\begin{array}{l}\text { Academi } \\
\text { c } \\
\text { intervent } \\
\text { ion }\end{array}$ & $\begin{array}{l}\text { Inattentio } \\
\mathrm{n} / \\
\text { Distractibi } \\
\text { lity }\end{array}$ & $\begin{array}{l}\text { Hyperacti } \\
\text { vity }\end{array}$ & $\begin{array}{l}\text { Disrupti } \\
\text { ve } \\
\text { Behavio } \\
\text { urs }\end{array}$ \\
\hline $\begin{array}{l}\text { Behaviour } \\
\text { intervention }\end{array}$ & - & $.54^{* *}$ & $.56^{* *}$ & .24 & .13 & .07 \\
\hline $\begin{array}{l}\text { Home/parent } \\
\text { intervention }\end{array}$ & & - & $.39^{* *}$ & .08 & .03 & -.03 \\
\hline $\begin{array}{l}\text { Academic } \\
\text { intervention } \\
\text { Inattention/Distrac }\end{array}$ & & & - & $.46^{* *}$ & .26 & .19 \\
\hline $\begin{array}{l}\text { tibility } \\
\text { Hyperactivity } \\
\text { Disruptive } \\
\text { Behaviours }\end{array}$ & & & & - & $\begin{array}{c}.70^{* *} \\
-\end{array}$ & $\begin{array}{l}.57^{* *} \\
.65^{* *}\end{array}$ \\
\hline
\end{tabular}




\section{Discussion}

The purpose of this study was to explore how teachers in the UAE identify children with ADHD and to examine the management strategies elementary school teachers in the UAE use to reduce ADHD behaviours. These research findings provide empirical support in relation to the factors teachers perceive contribute to their referral of students with ADHD. The results revealed that both general and special education teachers in the UAE perceived inattention/distractibility to be a contributing factor for referring students with ADHD to special education services, but not disruptive behaviour. This finding concurs with previous research (e.g., Gwernan-Jones et al., 2016; Ljusberg, 2011) that revealed that teachers lack knowledge of ADHD and the possible effects on the social and academic achievement of students with ADHD. Additionally, special education teachers in this study did not perceive hyperactivity to be a contributing factor. This could be because they feared that they might refer students with behavioural problems for special education services too quickly.

In relation to the management strategies that are frequently employed by special education and general education teachers in the UAE, the findings of this study revealed that in-service teachers often employed behaviour intervention and academic intervention management strategies. However, the home/parent intervention management strategy was commonly used only by special education teachers. The fact that general education teachers know less about intervention management strategies for students with ADHD corroborates findings of previous studies conducted in Africa (Blotnicky-Gallant et al., 2014) and Saudi Arabia (Abed et al., 2014). Besides, the MANOVA results revealed that the more experienced teachers used different management strategies, including behaviour intervention and home/parent intervention than the less experienced teachers. This finding concurs with Vereb and DiPerna (2004) who found a positive significant relationship between teachers' knowledge of ADHD, years of teaching experience with ADHD and medication acceptability. Additionally, post hoc analyses indicated that teachers with moderate experience with ADHD scored higher than inexperienced teachers in the hyperactive scale, which suggests that teachers with moderate experience perceived hyperactivity to be a contributing factor to refer students with ADHD to special education services. This finding is consistent with a previous cross-national study's findings, which found that prior experience with ADHD was associated with more teachers' knowledge of ADHD (Sciutto et al., 2016). With respect to the relationship between teachers' responses to the referral and management scales, the results revealed that there was a positive correlation between the academic intervention subscale and the inattention/distractibility subscale. Thus, the frequent use of academic intervention management strategies was positively related to in-service teachers' perceptions of the inattention/distractibility scale as a contributing factor to referring ADHD students to special services. This finding concurs with previous research, which revealed that appropriate classroom management strategies are linked to inservice teachers' knowledge base (Han \& Weiss, 2005). 


\section{Conclusion}

Findings of this study revealed that general and special education teachers lack knowledge of all contributing factors for ADHD referral. More specifically, general and special education teachers in this study did not perceive disruptive behaviour as a contributing factor. This finding may suggest that elementary school teachers in the UAE do not have adequate knowledge about the symptoms of ADHD. It is thus recommended that teacher training programmes may need to include more aspects of ADHD symptoms in their curriculum to equip teachers with the necessary knowledge to refer students to special education services. Previous researchers indicated that teacher training programs have a positive impact on increasing teachers' knowledge of ADHD and appropriate interventions for ADHD students (e.g., Alabd et al., 2018; Lasisi et al., 2017; Sciutto et al., 2016). Additionally, this study revealed that general education teachers in the UAE do not use home/parent intervention management strategies. It is imperative that all teachers in the UAE utilize multimodal intervention including advising parents, teacher intervention and child intervention because students with ADHD are a heterogeneous group. Thus, there is no single intervention that will enhance the functioning of all of these students in classrooms. It is also imperative that general education teachers in the UAE elementary schools know that research has revealed that advising and training parents on how to deal with their children with ADHD respond very positively to reducing these children's inappropriate behaviours. Additionally, managing students with ADHD behaviours is a complex issue that should take into account the students' academic, behavioural and home intervention strategies to address students' inappropriate behaviours when they emerge. The relationship between teachers' knowledge of ADHD and teaching experience has always been an important issue to consider as more experienced teachers have the ability to control inappropriate behaviours. In this study, probably the more experienced teachers' were less likely to refer children with attention deficits and hyperactivity symptoms because they are more skilful in managing and changing students' behaviours. It is recommended that future research addresses the various limitations of this study such as the small sample of elementary school teachers from six schools so that the findings can be generalized.

Acknowledgement: This research is funded by the Research Office at the United Arab Emirates University.

\section{References}

Abed, M., Pearson, S., Clarke, P., \& Chambers, M. (2014). Saudi Arabian teachers' knowledge and beliefs about ADHD. Journal of the International Association of Special Education, 15(1), 67-74.

Alabd, A. M., Mesbah, S. K., \& Alboliteeh, M. (2018). Effect of educational program on elementary school teachers' knowledge, attitude, and classroom management techniques regards attention deficit hyperactivity disorder. International Journal of Studies in Nursing, 3(3), 159-171. https:/ / doi.org/10.20849/ijsn.v3i3.528

Arcia, E., Frank, R., Sanchez-LaCay, \& Fernaindez, M. C. (2012). Teacher understanding of ADHD as reflected in attributions and classroom strategies. Journal of Attention Disorders, 4(2), 91-101. https:/ / doi.org/10.1177\%2F108705470000400203 
American Psychiatric Association (2013). Diagnostic and Statistical Manual of Mental Disorders (5th edition). Arlington, VA., American Psychiatric Association. Retrieved from https://www.adhd-health.com/adhd/adhd-dsm-iv-diagnosis

Barkley, R. (2020). Taking Charge of ADHD: The Complete, Authoritative Guide for Parents (4th edition). New York, NY: The Guilford Press.

Bener, A., Al Qahtani, R., \& Abdelaal, I. (2006). The prevalence of ADHD among primary school children in an Arabian society. Journal of Attention Disorders, 10(1), 77-82. https://doi.org/10.1177\%2F1087054705284500

Blotnicky-Gallant, P., Martin, C., McGonnell, M., \& Corkum, P. (2014). Nova Scotia teachers' ADHD knowledge, beliefs and classroom management practices. Canadian Journal of School Psychology, 30(1), 3-21. https://doi.org/10.1177/0829573514542225

Bu-Haroon, A., Eapen, V., \& Bener, A. (1999). The prevalence of hyperactivity symptoms in the United Arab Emirates. Nordic Journal of Psychiatry, 53(6), 439-442. Retrieved from https://www.researchgate.net/publication/289284099_The_prevalence_of_hyp eractivity_symptoms_in_the_United_Arab_Emirates

Cohen, J. (1988). Statistical Power Analysis for the Behavioral Sciences (2nd ed.). Hillsdale, NJ: Lawrence Erlbaum Associates, Publishers

Doernberg, E., \& Hollander, E. (2016). CNS Spectrums, 21, 295-299. Retrieved from https://www.cambridge.org/core

Drugli, M. B. (2013). How are closeness and conflict in student-teacher relationships associated with demographic factors, school functioning and mental health in Norwegian school children aged 6-13? Scandinavian Journal of Educational Research, 57(2), 217-225. https://doi.org/10.1080/00313831.2012.656276

DuPaul, G. J., Eckert, T. L., \& Vilardo, B. (2012). The effects of school-based interventions for attention deficit hyperactivity disorder: A meta-analysis 1996-2010. School Psychology Review, 41(4), 387-412. Retrieved from https://www.questia.com/library/journal/1G1-323144111/the-effects-ofschool-based-interventions-for-attention

Elhoweris, H. (2014). The effect of the label "giftedness" on United Arab Emirates preservice teachers' diagnosis decisions. International Journal of Education and Research, 2(11), 515-524. Retrieved from https://www.ijern.com/journal/2014/November-2014/42.pdf

Epstein, M., Atkins, M., Cullinan, D., Kutash, K., \& Weaver, R. (2008). Reducing behaviour problems in the elementary school classroom: A practice guide. Washington, DC: National Center for Education Evaluation and Regional Assistance, Institute of Education Sciences. Retrieved from https:/ / files.eric.ed.gov/fulltext/ED502720.pdf

Ewe, L. P. (2019). ADHD symptoms and teacher-student relationship: a systematic literature review: A systematic literature review. Emotional and Behavioural Difficulties, 24(2), 136-155. https:/ / doi.org/10.1080/13632752.2019.1597562

Fabiano, G., Pelham, W., Majumdar, A., Evans, S., Manos, M., Caserta, D., \& Carter, R. (2013). Elementary and middle school teacher perceptions of attention deficit/ hyperactivity disorder prevalence. Child \& Youth Care Forum, 42(2), 87-99. https://doi.org/10.1007/s10566-013-9194-1

Faraone, S. V., Asherson, P., Banaschewski, T., Biederman, J., Buitelaar, J. K., RamosQuiroga, J. A., \& Franke, B. (2015). Attention deficit/hyperactive disorder. Nature Review Diseases Primers, 1, 15020.

Friend, M., \& Bursuck, W. D. (2018). Including Students with Special Needs: A practical guide for classroom teachers ( $8^{\text {th }}$ edition). Boston, MA: Pearson. 
Gwernan-Jones, R., Moore, D., Cooper, P., Russell, A., Richardson, M., Rogers, M., Thompson-Coon, J., Stein, K., Ford, T., \& Garside, R. (2016). A systematic review and synthesis of qualitative research: The influence of school context on symptoms of Attention Deficit Hyperactivity Disorder. Emotional and Behavioural Difficulties, 21, 1-18. https:/ / doi.org/10.1080/13632752.2015.1120055

Han, S. S., \& Weiss, B. (2005). Sustainability of teacher implementation of school-based mental health programs. Journal of Abnormal Child Psychology, 33, 665-679. https://doi.org/10.1007/s10802-005-7646-2

Korpershoek, H., Harms, T., de Boer, H., van Kuijk, M., \& Doolaard, S. (2016). A Metaanalysis of the effects of classroom management strategies and classroom management programs on students' academic, behavioural, emotional, and motivational outcomes. Review of Educational Research, 86, 643-680. https://doi.org/10.3102\%2F0034654315626799

Lasisi, D., Ani, C., Lasebikan, V. Sheikh, L., \& Omigbodun, O. (2017). Effect of attentiondeficit-hyperactivity-disorder training program on the knowledge and attitudes of primary school teachers in Kaduna, North West Nigeria. Child Adolesc. Psychiatry Ment. Health, 11, 15. https://doi.org/10.1186/s13034-017-0153-8

Liu, A., Xu, Y., Yan, Q., \& Tong, L. (2018). The prevalence of attention deficit/hyperactivity disorder among Chinese children and adolescents. Scientific Reports, 8, 11169. https:/ / doi.org/10.1038/s41598-018-29488-2

Ljusberg, A.-L. (2011). The structured classroom. International Journal of Inclusive Education, 15(2), 195-210. http:/ / doi.org/10.1080/13603110902763433

Martinussen, R., Tannock, R., \& Chaban, P. (2011). Teachers' reported use of instructional and behaviour management practices for students with behaviour problems: relationship to role and level of training in ADHD. Child $\mathcal{E}$ Youth Care Forum, 40(3), 193-210. https:/ / doi.org/10.1007/s10566-010-9130-6

Miranda, A., Jarque, S., \& Tarraga, R. (2006). Intervention in school settings for students with ADHD. Exceptionality, 35-52. https://doi.org/10.1207/s15327035ex1401_4

Ohan, J., Visser, T. A. W., Strain, M. C., \& Allen, L. (2011). Teachers' and education students' perceptions of and reactions to children with and without the diagnostic Label "ADHD." Journal of School Psychology, 49(1), 81-105. https://doi.org/10.1016/j.jsp.2010.10.001

Öner, Ö., Vatanartiran, S., \& Karadeniz, S. (2019). Relationships between teacher-reported ADHD symptom profiles and academic achievement domains in a no referred convenience sample of first- to fourth-grade students. Psychiatry and Clinical

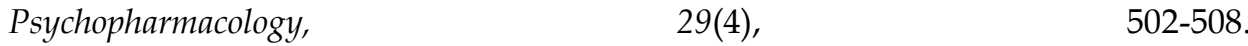
https:// doi.org/10.1080/24750573.2018.1457488

Owens, J. S., Coles, E. K., Evans, S. W., Himawan, L. K., Girio-Herrera, E., \& Schulte, A. C. (2017). Using multi-component consultation to increase integrity with which teachers implement behavioural classroom interventions. A pilot study. School Mental Health, 9(3), 218-234. https:/ / doi.org/10.1007/s12310-017-9217-4

Portilla, X. A., Ballard, P. J., Adler, N. E., Boyce, W. T., \& Obradovic, J. (2014). An integrative view of school functioning: Transactions between self-regulation, school engagement, and teacher-child relationship quality. Child Development, 85(5), 1915-1931. https://dx.doi.org/10.1111\%2Fcdev.12259

Poznanski, B., Hart, K. C., \& Cramer, E. (2018). Are teachers ready? Preservice teacher knowledge of classroom management and ADHD. School Mental Health, 10(3), 301-313.

Rabiner, D. L., Malone, P. S., \& the Conduct Problems Prevention Research Group (2004). The impact of tutoring on early reading achievement for children with and 
without attention problems. Journal of Abnormal Child Psychology, 32, 273-284. http:/ /dx.doi.org/10.1023/B:JACP.0000026141.20174.17

Reinke, W. M., Stormont, M., Herman, K. C., Puri, R., \& Goel, N. (2011). Supporting children's mental health in schools: Teacher perceptions of needs, roles, and barriers. School Psychology Quarterly, 26, 1-13. https://psycnet.apa.org/doi/10.1037/a0022714

Rushton, S., Giallo, R., \& Efron, D. (2019). ADHD and emotional engagement with school in the primary years: Investigating the role of student-teacher relationships. British Journal of Educational Psychology, 90(S1), 1-17. https://doi.org/10.1111/bjep.12316

Salehi, S., Noah, S., \& Jaafar, W. (2011). Primary school teachers' perceptions about attention deficit and sense of time among ADHD children. Paper presented at the $4^{\text {th }}$ International Conference of Cognitive Science, Tehran, Iran.

Salend, S. (2015). Creating Inclusive Classrooms: Effective and Reflective Practices for all Students ( $8^{\text {th }}$ ed.). Upper Saddle River, NJ: Pearson Merrill Prentice Hall.

Salend, S., Elhoweris, H., \& VanGarderen, D. (2003). Educational interventions for students with ADD. Intervention in School and Clinic, 38(5), 280-288. https://doi.org/10.1177\%2F10534512030380050301

Sciutto, M. J., Terjesen, M. D., Kučerová, A., Michalová, Z., Schmiedeler, S., Antonopoulou, K., Shaker, N. Z., Lee, J.-Y., Alkahtani, K., Drake, B., \& Rossouw, J. (2016). Cross-national comparisons of teachers' knowledge and misconceptions of ADHD. International Perspectives in Psychology: Research, Practice, Consultation, 5(1), 34-50. https://doi.org/10.1037/ipp0000045

Schultz, B., Storer, J., Watabe, Y., Sadler, J., \& Evans, S. (2011). School-based treatment of Attention-Deficit/Hyperactivity Disorder. Psychology in the Schools, 48(3), 254262. https://doi.org/10.1002/ pits.20553

Tannock, R., \& Martinussen, R. (2001). Reconceptualizing ADHD. Educational leadership, 59 (3), 20-25. Retrieved from http://www.ascd.org/publications/educationalleadership/nov01/vol59/num03/Reconceptualizing--ADHD.aspx

Vereb, R. L., \& DiPerna, J. C. (2004). Teachers' knowledge of ADHD, treatments for ADHD, and treatment acceptability: An initial investigation. School Psychology Review, 33(3), 421-428. 